\title{
Effects of respiratory viruses on febrile neutropenia attacks in children
}

\author{
Bilge Aldemir-Kocabaş ${ }^{1}$, Adem Karbuz ${ }^{1}$, Esra Pekpak ${ }^{2}$, Zeynep Ceren Karahan ${ }^{3}$, \\ İştar Dolapçı ${ }^{3}$, Elif İnce ${ }^{2}$, Zümrüt Uysal ${ }^{2}$, Gülsan Yavuz ${ }^{4}$, Ergin Çiftçi ${ }^{1}$, Erdal İnce ${ }^{1}$ \\ Departments of ${ }^{1}$ Pediatric Infectious Diseases, ${ }^{2}$ Pediatric Hematology, ${ }^{3}$ Medical Microbiology, ${ }^{4}$ Pediatric Oncology, Ankara \\ University Faculty of Medicine, Ankara, Turkey.E-mail: drbaldemir@gmail.com \\ Received: 28th April 2017, Revised: 1st June 2017, Accepted: 10th June 2017
}

SUMMARY: Aldemir-Kocabaş B, Karbuz A, Pekpak E, Karahan ZC, Dolapçı İ, İnce $\mathrm{E}$, Uysal Z, Yavuz G, Çiftçi E, İnce E. Effects of respiratory viruses on febrile neutropenia attacks in children. Turk J Pediatr 2017; 59: 511-519.

Respiratory tract viruses have an important effect on morbidity and mortality in patients with febrile neutropenia (FN). The aim of this study was to determine frequency and clinical influence of viral respiratory viruses as potential etiologic agents in episodes of FN in children. A total of 100 children (62 boys, 38 girls) with $166 \mathrm{FN}$ episodes were included in this prospective study. Nasopharyngeal aspirate samples were analyzed for respiratory viral agents using multiplex real-time polymerase chain reaction. The origin of the fever could be defined in $111(67 \%)$ of the episodes. We detected viral agents in $86(51.8 \%)$, bacterial agents in $19(11.4 \%)$, and fungal agents in $5(3 \%)$ of the episodes. The most common detected viruses were rhinovirus $(n=27)$, respiratory syncytial virus $(n=17)$, and coronavirus $(n=16)$. Parainfluenza virus, influenza A and B, adenovirus, human metapneumovirus, enterovirus, bocavirus and parechovirus were the remaining detected agents. More than one virus positivity occurred in $13 \mathrm{FN}$ episodes. Forty-three patients had multiple FN episodes. Only four patients had the same viral agent in consecutive attacks. Respiratory symptoms (cough, nasal discharge and congestion, sneezing, wheezing), physical examination signs (rales and rhonchi) and radiological findings were significantly more common in viral agent positive patients $(p<0.05)$. This study showed that respiratory viruses make a substantial contribution on the etiology of FN episodes in children. Identifying viral agents may help to constitute individualized infection-management algorithms in these patients.

Key words: children, fever, neutropenia, respiratory virus.

Febrile neutropenia (FN) is a common complication in patients with hematologic disorders, malignancy, and transplantation. As a result of intensive chemotherapy, surgery, radiotherapy and modern supportive care modalities, an increased probability of long term event-free survival has been achieved in pediatric cancer and bone marrow transplantation (BMT) patients. Although the source of fever can be severe infections in neutropenic patients, noninfectious factors can lead to fever, as well.1,2

Clinically documented infections are responsible $20 \%-30 \%$ of these febrile episodes and bacteremia occurs in $10 \%-25 \%$ of patients with FN. ${ }^{1-3}$ Despite advances in diagnostic modalities, the rates of unidentified etiology of fever and neutropenia have remained above 50 percent in the past decade $^{2}$. Recent studies have shown that respiratory tract viruses (RTVs) have an important effect on morbidity and mortality in febrile and neutropenic cases without a microbiologically documented agent. ${ }^{3-6}$ The laboratory diagnosis of RTVs is difficult and is traditionally based on antigen detection and virus isolation. Using conventional virus detection methods, RTVs can be identified in only $11 \%$ to $25 \%$ of children with FN. ${ }^{3}$ Utilizing polymerase chain reaction (PCR) techniques for viral detection has provided the advantage of increased sensitivity as compared to viral culture and antigen detection within a shorter time. 
The primary aim of this study was to evaluate the frequency, clinical influence and seasonal distribution of respiratory viral agents on FN episodes. Additionally, we investigated the contribution of bacterial and fungal agents to FN episodes, and analyzed the catheter infections and treatment modality choices.

\section{Material and Methods}

\section{Study population}

This study was conducted prospectively between September 2012 and May 2014 in the Pediatric Hematology and Oncology Department. All attacks were consulted with a Pediatric Infectious Disease specialist. The research procedure was approved by the local ethical committee. Parents were informed about the study and each parent provided a written consent to allow their child to participate in the study. All children with a neutropenic febrile episode were analyzed. Fever is defined as a single measurement of $>38.3^{\circ} \mathrm{C}$ (oral) or $\geq 38.5^{\circ} \mathrm{C}$ (axillary) or a temperature of $>38.0^{\circ} \mathrm{C}$ sustained over a $1-\mathrm{h}$ period. Neutropenia is defined as an absolute neutrophil count (ANC) of $<500$ cells $/ \mathrm{mm}^{3}$ or an ANC that is expected to decrease to $<500$ cells $/ \mathrm{mm}^{3}$ during the next 48 h.1,2 In order to compare the effect of ANC (below or over $500 / \mathrm{mm}^{3}$ ) on FN episodes with respect to RTV infections, durations of fever and total treatment, we also included patients with ANC $500-1,000 \mathrm{~mm}^{3}$ at the time of nasopharyngeal aspirate (NPA) obtaining and declined to $<500$ within $48 \mathrm{~h}$.

Exclusion criteria were: patients with ANC $>1,000 / \mathrm{mm}^{3}$, patients whose ANC did not declined to $<500$ within $48 \mathrm{~h}$, inadequate or inappropriate NPA samples, bleeding diathesis or nasopharyngeal tumor, thrombocytopenia $\left(<50,000 / \mathrm{mm}^{3}\right)$ despite supplementation, hemodynamic instability, loss of consciousness or convulsion, and less than 3 weeks between two febrile episodes.

A detailed physical examination was performed, and laboratory and radiologic tests were evaluated within 24 hours after each episode. Demographic and clinical data were obtained from medical records. We analyzed age, diagnosis, presence or absence of BMT, graft versus host disease (GVHD), comorbid diseases, viral symptoms, and physical examination signs, origin of fever, presence of central venous catheter, culture positivity, and viral agent positivity of the patients. Also, leukocyte, ANC, absolute lymphocyte count (ALC), hemoglobin, platelet counts, Creactive protein (CRP) level, $x$-ray findings, preferred antibiotics, durations of lymphopenia, neutropenia, fever and treatment were recorded.

\section{Data collection}

Nasopharyngeal aspirate samples were obtained from each patient during their hospitalization using a standardized procedure. Each respiratory specimen was taken by introducing at least 2 $\mathrm{ml}$ of sterile saline solution into the nasal fossa via 6 Fr nasogastric tubes (cut according to the patients' size). Samples were stored and processed according to the manufacturer's instructions. After total nucleic acid was extracted (EZ-1 Advanced, Qiagen, ABD) using EZ-1 Virus Kit v2.0 (Qiagen, ABD) viral genomes were investigated by multiplex real time PCR method (FTD Respiratory pathogens 21, Fast-track Diagnostics, Junglinster, Luxembourg) for influenza virus $\mathrm{A}$ and $\mathrm{B}$, $\mathrm{H} 1 \mathrm{~N} 1$, human coronavirus (HCoV) HKU, 229, 43, 63, parainfluenza virus (PIV) 1, 2, 3, and 4, human metapneumovirus ( $\mathrm{HMpV}) \mathrm{A}$ and $\mathrm{B}$, human rhinovirus (HRV), respiratory syncytial virus (RSV) type $A$ and $B$, enterovirus (EV), human parechovirus ( $\mathrm{HPeV}$ ), human bocavirus $(\mathrm{HBoV})$, and adenovirus (AdV).

\section{Statistical analysis}

Statistical analyses were performed using the SPSS software version 22.0. Descriptive statistics are presented by frequency, percent, mean, standard deviation and median, minimum, maximum values. The Pearson Chi-square test or Fisher's exact test (when Chi-square test assumptions do not hold due to low expected counts), where appropriate, was

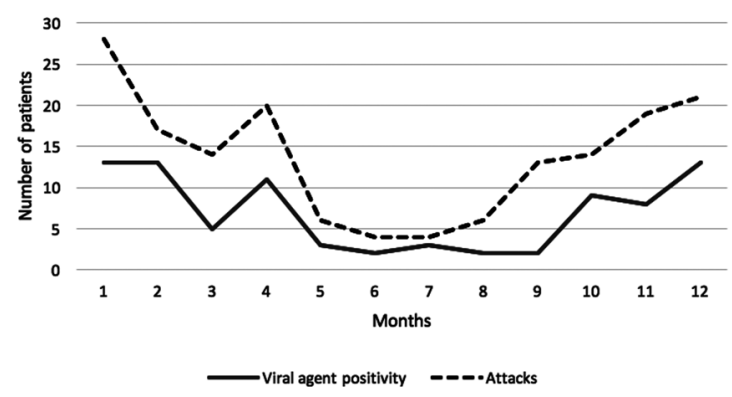

Fig. 1. Distribution of the identified respiratory viruses and all febrile neutropenia attacks by month. 
used to compare these proportions in different groups. The variables were investigated using visual and analytic methods (KolmogorowSimirnow/Shapiro-Wilks test) to determine whether or not they are normally distributed. Comparison of two groups was performed with non-parametric Mann-Whitney $U$ test because of abnormal distribution of the variables. A p-value of less than 0.05 was considered to show a statistically significant result.

\section{Results}

Table I shows demographic and clinical characteristics of the study population. A total of 100 children (62 boys, 38 girls) with
166 febrile neutropenia episodes were included in the study. Absolute neutrophil count was between $500-1,000 / \mathrm{mm}^{3}$ at the time of NPA samples were obtained in 32 patients. While the mean age was $90.4 \pm 63.1$ months, the mean age at diagnosis was $69 \pm 58.9$ months. The diagnoses of the patients were listed in Table I.

Six patients had co-morbid disease (Down syndrome in one, Noonan syndrome in one, diabetes mellitus in one, ataxia-telangiectasia in one, and congenital heart disease in two patients).

The origin of the fever could be defined in 111

Table I. Demographic and Basic Laboratory Data of the Patients and Febrile Neutropenia Episodes.

$\begin{array}{ll}\text { Patient enrolled, } \mathrm{n} & 100 \\ \text { Febrile neutropenia attacks, n } & 166 \\ \text { Age (months), mean } \pm \text { SD } & 90.4 \pm 63.1 \\ \text { Diagnosis age (months), mean } \pm \text { SD } & 69 \pm 58.9 \\ \text { Gender (male/female) } & 1.6 \\ \text { Diagnosis, n } & 53 \\ \quad \text { Hematologic malignancy } & 25 \\ \quad \text { Solid tumor } & 22 \\ \quad \text { Hematologic disorder } & 19 \\ \quad \text { Full-matched } & 15 \\ \text { Haploidentical } & 1 \\ \text { Autologous } & 3 \\ \left.\text { ANC (per mm }{ }^{3}\right), \text { median (range) } & 1,000(100-24,300) \\ \left.\text { ALC (per mm }{ }^{3}\right), \text { median (range) } & 100(0-1,000) \\ \text { Leukocyte count (per mm } 3 \text { transplantation patients, n } & 500(0-21,800) \\ \text { CRP level (mg/L), median (range) } & 12.1(0.1-449) \\ \text { Duration of neutropenia (days), median (range) } & 3(1-720) \\ \text { Duration of lymphopenia (days), median (range) } & 1(0-104) \\ \text { Duration of treatment (days), median (range) } & 10(4-180) \\ \text { Duration of fever (days), median (range) } & 2(0.5-12)\end{array}$

The most preferred antibiotics, $\mathrm{n}$

SBT-CPZ monotherapy 79

SBT-CPZ + amikacin combination $\quad 42$

Additional drugs as first line therapy, $\mathrm{n}$

$\begin{array}{ll}\text { Clarithromycin } & 16 \\ \text { Antifungal } & 27 \\ \text { Oseltamivir } & 12 \\ \text { Glycopeptid } & 34\end{array}$

ANC: absolute neutrophil count, ALC: absolute lymphocyte count, CRP: C-reactive protein, SBT-CPZ: sulbactam-cefoperazone. 
(67\%) of the FN episodes; upper respiratory tract infections (URTI) in 38 (34.2\%), lower respiratory tract infections (LRTI) in $6(5.4 \%)$, URTI + LRTI in 12 (10.9\%), URTI + blood stream infection (BSI) in $4(3.6 \%)$, catheter infections in $15(13.5 \%)$ (13 catheter-related bloodstream infection [CRBSI], 1 port exit site infection, 1 catheter tunnel infection), mucositis in $18(16.2 \%)$, BSI in $1(0.9 \%)$, disseminated zona in $1(0.9 \%)$, acute gastroenteritis in 3 $(2.7 \%)$, acute respiratory distress syndrome (ARDS) in $1(0.9 \%)$, urinary tract infection (UTI) in $(0.9 \%)$, engraftment syndrome in 1 $(0.9 \%)$, typhlitis in $4(3.6 \%)$, typhlitis + BSI in $1(0.9 \%)$, hepatosplenic candidiasis in 1 $(0.9 \%)$, hepatosplenic candidiasis + BSI in 1 $(0.9 \%)$, cellulitis in $1(0.9 \%)$, parotitis in 1 $(0.9 \%)$, and intracranial abscess in $1(0.9 \%)$ of the episodes.
Blood culture positivity was found in 19 episodes (11.4\%). Gram negative agents were positive in 10 (Pseudomonas aeruginosa in one, Klebsiella pneumoniae in three, Serratia marcescens in one, Escherichia coli in three, Acinetobacter baumannii in one, Ochrobactrum anthropi in one); gram positive microorganisms were positive in 7 (coagulase-negative staphylococci in five, alphahemolytic streptococci in two); and candida was positive in 2 (Candida parapsilosis and Candida kefyr) of these episodes. Additionally, UTI due to $E$. coli in one patient and intracranial abscess due to $S$. aureus in another patient were the origin of the fever. We detected viral agent in $86(51.8 \%)$, bacterial agent in $19(11.4 \%)$, and fungal agent in $5(3 \%)$ attacks (two in blood, two in tracheal aspirate, and one in blood and tissue biopsy). Six of 166 FN episodes (3.6\%) had both viral and bacterial agent positivity.

Table II. Respiratory Virus Diagnostic Results of Febrile Neutropenia Episodes (n: 166).

\begin{tabular}{|c|c|}
\hline & n (\%) \\
\hline Positive viral tests & $86(51.8)$ \\
\hline Single virus detected & $73(44.0)$ \\
\hline Multiple viruses detected & $13(7.8)$ \\
\hline \multicolumn{2}{|l|}{ Single viral agents } \\
\hline HRV & $22(13.3)$ \\
\hline Influenza A & $6(3.6)$ \\
\hline AdV & $5(3.0)$ \\
\hline RSV & $12(7.2)$ \\
\hline $\mathrm{HCoV}$ & $14(9.0)$ \\
\hline PIV & $7(4.2)$ \\
\hline $\mathrm{HMpV}$ & $3(1.8)$ \\
\hline Influenza B & $1(0.6)$ \\
\hline $\mathrm{EV}$ & $2(1.2)$ \\
\hline $\mathrm{HPeV}$ & $1(0.6)$ \\
\hline \multicolumn{2}{|l|}{ Multiple viral agents } \\
\hline Influenza A + RSV & $4(2.4)$ \\
\hline $\mathrm{HRV}+\mathrm{PIV}$ & $2(1.2)$ \\
\hline $\mathrm{HRV}+\mathrm{HBoV}$ & $1(0.6)$ \\
\hline $\mathrm{HRV}+\mathrm{HCoV}$ & $1(0.6)$ \\
\hline $\mathrm{PIV}+\mathrm{HCoV}$ & $1(0.6)$ \\
\hline $\mathrm{HMpV}+\mathrm{HBoV}$ & $1(0.6)$ \\
\hline $\mathrm{HRV}+\mathrm{AdV}$ & $1(0.6)$ \\
\hline Influenza A + PIV & $1(0.6)$ \\
\hline $\mathrm{PIV}+\mathrm{RSV}+\mathrm{AdV}$ & $1(0.6)$ \\
\hline
\end{tabular}

HRV: human rhinovirus, AdV: adenovirus, RSV: respiratory syncytial virus, HCoV: human coronavirus, PIV: parainfluenza virus, $\mathrm{HMpV}$ : human metapneumovirus, EV: enterovirus, HPeV: human parechovirus, HBoV: human bocavirus. 
We detected viral agents in 86 (51.8\%) episodes (Table II). Viral and bacterial agent positivity was found in six of 166 attacks (3.6\%). The most common viral agents were HRV $(n=27)$ RSV $(n=17)$, and HCoV $(n=16)$. The frequency of FN episodes was increased in winter and

Table III. Viral Agent Distribution After Viral Agent Positivity in the Repeated Samplings of the Patients with Recurrent Febrile Neutropenia Episodes.

\begin{tabular}{|c|c|c|c|c|c|}
\hline No & Virus & Age (months) & No & Virus & Age (months) \\
\hline \multirow[t]{2}{*}{1} & HRV & 14 & 15 & PIV & 137 \\
\hline & None & 20 & & HRV & 138 \\
\hline \multirow[t]{4}{*}{2} & $\mathrm{HCoV}$ & 25 & & None & 140 \\
\hline & None & 27 & & RSV & 142 \\
\hline & RSV & 29 & 16 & $\mathrm{HMpV}$ & 99 \\
\hline & None & 38 & & HRV & 102 \\
\hline \multirow[t]{2}{*}{3} & AdV & 131 & 17 & $\mathrm{HCoV}$ & 13 \\
\hline & None & 132 & & HRV & 15 \\
\hline \multirow[t]{3}{*}{4} & RSV & 69 & 18 & HRV & 61 \\
\hline & None & 71 & & HRV & 66 \\
\hline & None & 80 & & $\mathrm{HCoV}$ & 67 \\
\hline \multirow[t]{2}{*}{5} & Influenza $\mathrm{A}+\mathrm{RSV}$ & 96 & 19 & HRV & 18 \\
\hline & PIV & 99 & & None & 19 \\
\hline \multirow[t]{3}{*}{6} & HRV & 167 & & None & 21 \\
\hline & None & 170 & 20 & Influenza A+RSV & 3 \\
\hline & HRV & 175 & & None & 8 \\
\hline \multirow[t]{3}{*}{7} & HRV & 167 & & $\mathrm{HRV}+\mathrm{PIV}$ & 14 \\
\hline & None & 170 & 21 & None & 6 \\
\hline & HRV & 175 & & PIV & 7 \\
\hline \multirow[t]{2}{*}{8} & RSV & 33 & & PIV & 11 \\
\hline & $\mathrm{HCoV}$ & 47 & 22 & None & 125 \\
\hline \multirow[t]{3}{*}{9} & PIV & 22 & & $\mathrm{HCoV}$ & 128 \\
\hline & HRV & 24 & & $\mathrm{AdV}$ & 131 \\
\hline & None & 25 & 23 & HRV & 52 \\
\hline \multirow[t]{6}{*}{10} & AdV & 67 & & PIV & 59 \\
\hline & None & 69 & 24 & RSV & 23 \\
\hline & None & 73 & & $\mathrm{HCoV}$ & 25 \\
\hline & $\mathrm{HCoV}$ & 75 & 25 & HRV & 167 \\
\hline & None & 76 & & None & 170 \\
\hline & None & 78 & & HRV & 175 \\
\hline \multirow[t]{2}{*}{11} & HRV & 63 & & None & 176 \\
\hline & RSV & 65 & & $\mathrm{HMpV}$ & 180 \\
\hline \multirow[t]{2}{*}{12} & HRV & 162 & 26 & $\mathrm{HCoV}$ & 110 \\
\hline & RSV & 172 & & HRV & 121 \\
\hline \multirow[t]{2}{*}{13} & $\mathrm{HCoV}$ & 30 & 27 & HRV & 128 \\
\hline & $\mathrm{HCoV}$ & 32 & & RSV & 139 \\
\hline \multirow[t]{2}{*}{14} & Influenza $\mathrm{A}+\mathrm{RSV}$ & 20 & 28 & HRV & 60 \\
\hline & PIV & 21 & & HRV & 74 \\
\hline
\end{tabular}

HRV: human rhinovirus, AdV: adenovirus, RSV: respiratory syncytial virus, HCoV: human coronavirus, PIV: parainfluenza virus, $\mathrm{HMpV}$ : human metapneumovirus. 
autumn, and decreased in summer as parallel to the viral epidemiological distribution (Fig. 1). Forty-three patients had multiple FN episodes (29 had two, 9 had three, 2 had four, 2 had five, and 1 had six episodes) (Table III). When we analyzed 28 of them (who had an additional episode after a RTV positivity), we showed that only four patients had same viral agent in consecutive attacks. They had viral symptoms in each episode. Remaining 15 patients had either no RTV positivity or only one detected viral agent after one or more negative PCR results.

The proportions of the symptoms and physical examination signs in patients with and without viral agent positivity were listed in Table IV. Cough $(p<0.01)$, nasal discharge $(p<0.01)$, nasal congestion $(p<0.01)$, sneezing $(p<0.01)$, wheezing $(\mathrm{p}=0.01)$, rales $(\mathrm{p}<0.001)$ and rhonchi $(p<0.001)$ were statistically significantly more common symptoms and signs in the viral agent positive group. Also, radiological sign positivity was higher in this group $(p=0.03)$.

The median ANC was significantly higher in the viral agent positive patients compared to negative ones $\left(200 / \mathrm{mm}^{3}\right.$ vs. $100 / \mathrm{mm}^{3}$, $\mathrm{p}=0.03)$. There were not significant differences in these patients in terms of the durations of lymphopenia and neutropenia, CRP level, and median ALC ( $p$ >0.05).

Comparisons of the patients with ANC $\leq 500 /$ $\mathrm{mm}^{3}$ and $>500 / \mathrm{mm}^{3}$ in terms of clinical and laboratory parameters during FN episodes were shown in Table $\mathrm{V}$. We did not find a significant difference for viral agent positivity between these groups $(p=0.48)$. However, patients with ANC $>500 / \mathrm{mm}^{3}$ more commonly had X-ray findings than ANC $\leq 500 / \mathrm{mm}^{3}$ group $(p=$ 0.005). Similarly, comparison of the patients with ALC $\leq 1000 / \mathrm{mm}^{3}$ and $>1000 / \mathrm{mm}^{3}$ in terms of CRP levels and duration of fever were as following: $13.5 \mathrm{mg} / \mathrm{L}$ (1-449) vs. 11.8 $\mathrm{mg} / \mathrm{L}(0.1-192)$, respectively $(\mathrm{p}=0.32)$ and 3 days (0.5-12) vs. 2 days (0.5-7), respectively $(p=0.12)$. There was no significant difference between two groups in terms of viral agent $(p=0.6)$ and $x$-ray $(p=0.51)$ positivity. However, duration of treatment was significantly longer in the latter group $(\mathrm{p}=0.04)$.

Although the patients with culture positivity had higher median CRP values than those with

Table IV. Comparison of Symptoms and Signs Between Respiratory Virus (+) and (-) Groups.

\begin{tabular}{llll}
\hline & $\begin{array}{l}\text { Respiratory virus }(+) \\
\text { group (\%) }\end{array}$ & $\begin{array}{l}\text { Respiratory virus (-) } \\
\text { group (\%) }\end{array}$ & p \\
\hline Symptoms & & & $<0.001$ \\
Cough & 50.0 & 12.2 & $<0.001$ \\
Nasal discharge & 50.0 & 9.8 & $<0.001$ \\
Nasal congestion & 27.4 & 3.7 & $<0.001$ \\
Sneezing & 50 & 11.0 & 0.01 \\
Wheezing & 15.5 & 1.2 & 0.9 \\
Chest pain & 3.6 & 2.4 & 0.8 \\
Dyspnea & 7.1 & 6.1 & 0.9 \\
Myalgia & 4.8 & 2.4 & 0.5 \\
Conjunctivitis & 1.0 & 0 & $<0.001$ \\
Signs & & & $<0.001$ \\
Rales & 28.6 & 6.1 & 0.03 \\
Rhonchi & 22.6 & 1.2 & 0.2 \\
X-ray positivity & 23.8 & 11.0 & 0.6 \\
Tachypnea & 15.5 & 8.5 & 0.8 \\
Retraction & 9.5 & 7.3 & 0.5 \\
Hypoxemia & 8.3 & 7.3 & 0.7 \\
Tachycardia & 3.6 & 6.1 & \\
Hypotension & 2.4 & 3.7 & \\
\hline
\end{tabular}


Table V. Comparison of the Patients with ANC $<500 / \mathrm{mm}^{3}$ and $500-1,000 / \mathrm{mm}^{3}$.

\begin{tabular}{llll}
\hline & ANC $<500 / \mathrm{mm}^{3}$ & ANC 500-1,000/. $\mathrm{m}^{3}$ & $\mathrm{p}$ \\
\hline Number of FN episodes & 134 & 32 & \\
Duration of fever (days), median (range) & $2(0.5-12)$ & $2(0.5-7)$ & 0.49 \\
Duration of treatment (days), median (range) & $10(4-107)$ & $10(4-180)$ & 0.58 \\
CRP (mg/L), median (range) & $13.5(0.1-449)$ & $10.4(1-160)$ & 0.2 \\
Viral agent positivity & $49.3 \%$ & $56.3 \%$ & 0.48 \\
Blood culture positivity & $11.9 \%$ & $18.8 \%$ & 0.38 \\
X-ray positivity & $13.4 \%$ & $34.4 \%$ & 0.005 \\
\hline
\end{tabular}

ANC: absolute neutrophil count, CRP: C-reactive protein, FN: febrile neutropenia

viral agent positivity, it was not statistically significant $(p=0.12)$. On the other hand, neither duration of fever nor x-ray finding positivity were significantly different $(p=0.07$ and $\mathrm{p}=0.8$, respectively). Unlike, duration of treatment was significantly longer in patients with culture positivity $(\mathrm{p}<0.001)$.

In a total of $122 \mathrm{FN}$ episodes $(73.5 \%)$ the patients had central venous catheter (Hickmann in $75 \%$ and port catheter in $25 \%$ ). Catheterrelated bloodstream infections occurred in $13(10.7 \%)$ of these patients. Catheter lock therapy (CLT) (with amikacin in three and vancomycin in four) was performed in seven $(53.8 \%)$ of the patients with CRBSIs. CLT was successful in five attacks and catheters could be rescued in these patients. The catheters were withdrawn due to septic shock in two patients, CLT failure in two patients, culture positivity for candida and acinetobacter in two patients with CRBSIs, and exit site and tunnel infections in two patients.

\section{Discussion}

Fever in the setting of neutropenia is often initial and potentially the only clinical sign of a bacterial, fungal, or viral infection. Previous descriptive pediatric studies confirmed that the depth and duration of neutropenia was a risk factor for developing infection. ${ }^{1-3}$ Because clinical syndromes in the immunocompromised host are often nonspecific, laboratory detection of respiratory viral pathogens is essential for the diagnosis in these patients. A high incidence of respiratory viral infections occurs in children with hematologic malignancies and BMT, especially during periods of neutropenia. ${ }^{1-4}$ There have been few studies that have analyzed the frequency of the respiratory viruses during these episodes. ${ }^{3,6-14}$ However, majority of them were retrospective, conducted in relatively small patient groups, and used conventional methods for identifying viral agents. Using PCR-techniques for viral detection allows advantage of increased sensitivity in a shorter time as compared to viral culture and antigen detection. We showed a high frequency of RTVs in a relatively large number of FN episodes by multiplex real time PCR method in this prospective study.

Infections are the major cause of morbidity and mortality in children with neutropenia secondary to chemotherapy. Identification of neutropenic episodes and initiating empirical broad-spectrum antibiotics promptly have reduced mortality below 5\%. ${ }^{5}$ It has been reported that mortality rate is three times higher in patients with ANC $<100 / \mathrm{mm}^{3}$ than those with $>1000 / \mathrm{mm}^{3} .^{1,2}$ However, origin of the fever cannot be defined in the majority of these cases. Historically the most frequent infections have been related to bacterial and fungal agents but more recently respiratory viruses have received increased attention as major pathogens in neutropenic patients. ${ }^{14-17}$ Indeed, respiratory viral agent positivity was $51.8 \%$ and both viral and bacterial agent positivity was $3.6 \%$ in our study. Supporting our results, Suryadevara et al. ${ }^{3}$ reported this ratio as $52 \%$. Few studies are available regarding this issue with lower frequencies of viral agents. Öhrmalm et al. ${ }^{12}$ showed that $18.1 \%$ of FN patients had at least one viral agent in NPA samples in an adult study group. Remaining reports which were conducted in FN or BMT patients have reported respiratory virus frequency as a ratio of between $23 \%$ and $32 \% .5,18-20$ While distribution of responsible viral respiratory agents varies between different studies, the most common detected viruses were HRV and RSV in the present study.5,18-21 
The duration of neutropenia is also very important risk factor for both bacterial and fungal infections during FN episodes. But the relationship between the duration of neutropenia and frequency of viral infections remains unknown. The durations of lymphopenia and neutropenia between RTV positive and negative groups were similar in our study $(p>0.05)$. On the other hand, characteristic symptoms, clinical signs and radiologic findings of RTV infections were significantly more common in viral agent positive patients.

Signs and symptoms of inflammation are often faint or absent especially in profound neutropenic patients. These findings occur more commonly with increasing neutrophil counts. ${ }^{1,2}$ Supporting this data, the median ANC count was significantly higher in the viral agent positive group compared to negative group in our study $(\mathrm{p}=0.03)$. Also, signs and symptoms were more prominent in these patients. Moreover, x-ray findings were more common in patients with ANC $>500 / \mathrm{mm}^{3}$ than ANC $\leq 500 / \mathrm{mm}^{3}$ group $(\mathrm{p}=0.005)$.

We also investigated the effect of viral agent positivity on the empiric antibiotic treatment duration in FN patients. We showed that duration of treatment was significantly shorter in viral agent positive patients than bacterial agent positive ones. A positive viral test can allow us discontinuation of broad-spectrum antibiotics in FN patients with no culture positivity and low risk according to FN guidelines.

One limitation of our study is the question whether the detected viral nucleic acid actually represents the direct causative agent of FN. A subclinical infection or intracellular nonreplicating viral nucleic acid remnants can easily cause PCR positivity. However, viral agent positive patients more commonly had viral symptoms, supporting an active infection in our study. On the other hand, post-infection viral shedding also can cause a positive viral PCR. Indeed, prolonged viral shedding of RSV, HRV and influenza $\mathrm{A}$ has been reported in children with cancer and transplantation. ${ }^{5,17}$ But, only 4 of 28 patients with recurrent FN attacks had the same virus positivity in consecutively sampled NPAs in this study. Although it is possible to represent a delayed viral shedding, it might be a result of second infection with the same agent, as well. Presence of viral symptoms in each FN episode supports the latter probability. Other limitations are presence of a small number of patients having ANC $\geq 500 \mathrm{~mm}^{3}$ to compare the patients those with ANC $<500 \mathrm{~mm}^{3}$ and lack of viral culturing.

In conclusion, this study showed that respiratory viral agents make a substantial contribution to the etiology of FN episodes in children. Although the treatment is limited by supportive therapy modalities in majority of these agents currently, awareness of causal relationship and the impact of viral infections on neutropenic children would provide us ease for management of FN attacks, especially in low risk patients. An increase in the diagnostic and therapeutic approaches for respiratory viruses and more comprehensive studies are needed for detailed guide-line data in this patient population.

\section{REFERENCES}

1. Freifeld AG, Bow EJ, Sepkowitz KA, et al. Infectious Diseases Society of America. Clinical practice guideline for the use of antimicrobial agents in neutropenic patients with cancer: 2010 Update by the Infectious Diseases Society of America. Clin Infect Dis 2011; 52: 427-431.

2. Fisher BT, Sung L. The febrile neutropenic patient. In: Cherry JD, Harrison GJ, Kaplan SL, Steinbach WJ, Hotez PJ (eds). Feigin and Cherry's Textbook of Pediatric Infectious Diseases (7th ed) Vol. 1. Philadelphia: Elsevier Saunders, 2014: 921-933.

3. Suryadevara M, Tabarani CM, Bartholoma N, et al. Nasopharyngeal detection of respiratory viruses in febrile neutropenic children. Clin Pediatr (Phila) 2012; 51: 1164-1167.

4. Marcone DN, Ellis A, Videla C, et al. Viral etiology of acute respiratory infections in hospitalized and outpatient children in Buenos Aires, Argentina. Pediatr Infect Dis J 2013; 32: 105-110.

5. Lindblom A, Bhadri V, Söderhäll S, et al. Respiratory viruses, a common microbiological finding in neutropenic children with fever. J Clin Virol 2010; 47: 234-237.

6. Uys R, Cotton MF, Wessels G, et al. Viral isolates during febrile neutropaenia in children with cancer. J Trop Pediatr 2000; 46: 21-24.

7. Wood DJ, Corbitt G. Viral infections in childhood leukemia. J Infect Dis 1985; 152: 266-273.

8. Long DR, Craft AW, Kernahan J, et al. Virus infections in childhood malignant disease. Pediatr Hematol Oncol 1987; 4: 283-292.

9. Arola M, Ruuskanen O, Ziegler T, Salmi TT. Respiratory virus infections during anticancer treatment in children. Pediatr Infect Dis J 1995; 14: 690-694. 
10. Möttönen $M$, Uhari $M$, Lanning $M$, Tuokko $H$. Prospective controlled survey of viral infections in children with acute lymphoblastic leukemia during chemotherapy. Cancer 1995; 75: 1712-1717.

11. Koskenvuo M, Möttönen M, Rahiala J, et al. Respiratory viral infections in children with leukemia. Pediatr Infect Dis J 2008; 27: 974-980.

12. Ohrmalm L, Wong $M$, Aust $C$, et al. Viral findings in adult hematological patients with neutropenia. PLoS One 2012; 7: e36543.

13. Srinivasan A, Gu Z, Smith T, et al. Prospective detection of respiratory pathogens in symptomatic children with cancer. Pediatr Infect Dis J 2013; 32: e99-e104.

14. Kuypers J, Campbell AP, Cent A, et al. Comparison of conventional and molecular detection of respiratory viruses in hematopoietic cell transplant recipients. Transpl Infect Dis 2009; 11: 298-303.

15. Shah DP, Shah PK, Azzi JM, Chemaly RF. Parainfluenza virus infections in hematopoietic cell transplant recipients and hematologic malignancy patients: A systematic review. Cancer Lett 2016; 370: 358-364.
16. Hsu JW, Wingard JR. Advances in the management of viral infections. Cancer Treat Res 2014; 161: 157-180.

17. Weigt SS, Gregson AL, Deng JC, et al. Respiratory viral infections in hematopoietic stem cell and solid organ transplant recipients. Semin Respir Crit Care Med 2011; 32: 471-493.

18. Martino R, Piñana JL, Parody R, et al. Lower respiratory tract respiratory virus infections increase the risk of invasive aspergillosis after a reduced-intensity allogeneic hematopoietic SCT. Bone Marrow Transplant 2009; 44: 749-756.

19. Peck AJ, Englund JA, Kuypers J, et al. Respiratory virus infection among hematopoietic cell transplant recipients: evidence for asymptomatic parainfluenza virus infection. Blood 2007; 110: 1681-1688.

20. Täger F M, Zolezzi R P, Folatre B I, et al. Respiratory virus infections in children with acute lymphoblastic leukemia and febrile neutropenia: A prospective study. Rev Chilena Infectol 2006; 23: 118-123.

21. Alvares PA, Berezin EN, Botelho AC, et al. Coronaviruses in children with febrile neutropenia. Braz J Infect Dis 2014; 18: 98-99. 